\title{
$\beta$-thalassemia caused by compound heterozygous mutations and cured by bone marrow transplantation: A case report
}

\author{
LIUSONG WU ${ }^{1 *}$, ZHIYU PENG ${ }^{2 *}$, SEN LU $^{2}$, MEI TAN ${ }^{1}$, YING RONG $^{1}$,

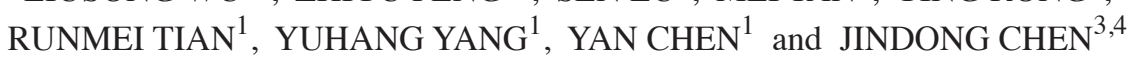 \\ ${ }^{1}$ Department of Pediatrics, Affiliated Hospital of Zunyi Medical University, Zunyi, Guizhou 563000; \\ ${ }^{2}$ Beijing Genomics Institute-Shenzhen, Shenzhen, Guangdong 518000, P.R. China; ${ }^{3}$ Department of \\ Urology, University of Rochester Medical Center, Rochester, NY 14642, USA; ${ }^{4}$ Department of \\ Medical Genetics, Zunyi Medical University, Zunyi, Guizhou 563000, P.R. China
}

Received September 23, 2016; Accepted May 25, 2017

DOI: $10.3892 / \mathrm{mmr} .2017 .7476$

\begin{abstract}
In the present study, a rare familial case of severe thalassemia with compound spontaneous mutations is reported. A 2.5-year-old boy, who suffered from severe anemia with yellowish skin, enlarged liver and spleen, was provided with a blood transfusion every 20 days to maintain hemoglobin levels between 90 and $100 \mathrm{~g} / \mathrm{l}$. Sanger sequencing combined with reverse transcription-quantitative polymerase chain reaction (RT-qPCR) and Gap-PCR revealed that the proband was a carrier of 4 compound heterozygous mutations: Hemoglobin subunit $\beta(H B B)$ :IVS-II-654(C>T) $\beta^{+}$; Southeast Asian-type-hereditary persistence of fetal hemoglobin (SEA-HPFH); $H B B: c 316-148 \mathrm{G}>\mathrm{T}$; hemoglobin subunit $\alpha 2$ (HBA2):c.46G $>$ A. The father of the proband was identified as a carrier of the heterozygous SEA-HPFH mutation, the mother was a carrier of compound heterozygous mutations of $H B B$ :IVS-II-654(C>T) and $H B A 2: c .46 \mathrm{G}>\mathrm{A}$, and the elder sister was heterozygous for $H B B$ :IVS-II- $654(\mathrm{C}>\mathrm{T}) \beta^{+}$. Based on these genetic results, it was determined that the proband had both of heavy $\beta$-thalassemia and $\alpha$-thalassemia. Upon human leukocyte antigen matching, bone marrow transplantation (BMT) was successfully performed on the proband by selecting his HLA-compatible sister as a donor. Following treatment, the proband was revealed to only carry
\end{abstract}

Correspondence to: Professor Yan Chen, Department of Pediatrics, Affiliated Hospital of Zunyi Medical University, 201 Dalian Road, Zunyi, Guizhou 563000, P.R. China

E-mail: cyz600@163.com

Professor Jindong Chen, Department of Urology, University of Rochester Medical Center, 601 Elmwood Avenue, Rochester, NY 14642, USA

E-mail: jindong_chen@hotmail.com

${ }^{*}$ Contributed equally

Key words: $\beta$-thalassemia, $\alpha$-thalassemia, $\beta$-globin gene, mutation, bone marrow transplantation the IVS-II-654(C>T) $\beta^{+}$heterozygous mutation, and further regular blood transfusions have been avoided; BMT results remained normal at six months follow-up.

\section{Introduction}

Thalassemia is an inherited hemoglobinopathy that is caused by an imbalance in the ratio of $\alpha$-globin and $\beta$-globin synthesis, which results in hemolytic anemia owing to the shortened lifespan of red blood cells (1). Clinically, $\alpha$ - and $\beta$-thalassemias occur as a result of genetic defects (2). $\beta$-thalassemia is characterized by a defect in the synthesis of $\beta$-globin chains of the hemoglobin tetramer. Mutations in the hemoglobin subunit $\beta(H B B)$ gene lead to an abnormal formation of hemoglobin, which results in improper oxygen transportation and the destruction of red blood cells. These mutations either partially or completely terminate $\beta$-globin chain synthesis, which are classified as $\beta^{+}$ and $\beta^{0}$ mutations, respectively. Every year, $~ 60,000$ newborns are diagnosed with $\beta$-thalassemia worldwide $(3,4)$. The type of genetic mutation and distribution frequency of $\beta$-thalassemia exhibits obvious regional differences and ethnic characteristics. High incidence rates of $\beta$-thalassemia have been reported in the southern China $(3,4)$, and the carrier rates of the populations of those regions were $3-24 \%$. Currently, $>200$ types of $\beta$-globin gene mutations have been identified around the world, and $>30$ mutations have been recorded in China (5). A previous study demonstrated that compound mutations may lead to severe thalassemia or thalassemia intermedia (6). Many of these compound mutations are familial alterations, and spontaneous somatic mutations are quite rare. The present study reported a case of compound heavy $\beta$-thalassemia plus $\alpha$-thalassemia caused by both familial and somatic mutations. To treat the proband, all family members of the patient were subjected to human leukocyte antigen (HLA) typing, and bone marrow transplantation (BMT) was successfully performed between the proband and his HLA-identical sister.

\section{Case report}

Written informed consent was obtained from all participants in the present study. The proband was a boy (age, 2 years 
6 months) with severe anemia (hemoglobin level, $62 \mathrm{~g} / \mathrm{l}$ ) accompanied by yellowish skin, enlarged liver and spleen, among other symptoms present since he was 6 months old. Based on these clinical and hematological characteristics (Table I), the patient was diagnosed with heavy $\beta$-thalassemia (2). Sanger sequencing was performed to identify any mutations in the proband and other family members. To conduct Sanger sequencing, three pairs of polymerase chain reaction (PCR)/sequencing primers were designed for hemoglobin subunit $\alpha 1$ (HBA1), HBA2 and hemoglobin subunit $\beta$ (HBB; PCR primer sequences are patented and withheld by the Beijing Genomics Institute-Shenzhen, Shenzhen, Guangdong, China). Genomic DNA was extracted from peripheral blood using the PureLink ${ }^{\mathrm{TM}}$ Genomic DNA Mini kit (cat. no. K182000; Invitrogen; Thermo Fisher Scientific, Inc., Waltham, MA, USA) according to the manufacturer's instructions. The PCR mixture was prepared in a $25 \mu \mathrm{l}$ reaction solution containing $0.4 \mu \mathrm{M}$ of each primer, $25 \mathrm{ng}$ genomic DNA and $12.5 \mu \mathrm{l}$ 2X GoldStarTaq Master Mix (CWBiotech, Beijing, China). PCR was performed in a ABI 9700 PCR machine (Applied Biosystems; Thermo Fisher Scientific, Inc.) with the following thermocycling conditions: An initial hot-start step at $95^{\circ} \mathrm{C}$ for $10 \mathrm{~min}$, followed by 35 cycles of $30 \mathrm{sec}$ at $95^{\circ} \mathrm{C}, 30 \mathrm{sec}$ at $60^{\circ} \mathrm{C}$ and $90 \mathrm{sec}$ at $72^{\circ} \mathrm{C}$, and a final extension of $10 \mathrm{~min}$ at $72^{\circ} \mathrm{C}$. The PCR products were purified using Centricon ${ }^{\circledR}-100$ columns (cat. no. P/NN930-2119; EMD Millipore, Billerica, MA, USA) according to the manufacturer's protocol, and then sequenced using the ABI 3730xl DNA Analyzer (Applied BioSystems; Thermo Fisher Scientific, Inc.). The sequencing results were analyzed using Lasergene software v7.1 (DNASTAR, Inc., Madison, WI, USA). These analyses demonstrated that the proband was a carrier of the thalassemia gene mutation IVS-II-654(C>T) $\beta^{+}$. To further diagnose the proband and their family members, additional blood tests with Sysmex XE-5000 Automatic Hematology Analyzer and Sebia automatic electrophoresis were performed. Peripheral blood $(\sim 2 \mathrm{ml})$ was collected from each individual, maintained in tubes with EDTA anticoagulant, subjected to blood cell examination using the Sysmex XE-5000 analyzer (Sysmex Corporation, Kobe, Japan) and then analyzed using Laboman EasyAccess v4.2 software (Sysmex Corporation). For Sebia automatic electrophoresis, $2 \mathrm{ml}$ peripheral blood was collected and centrifuged at $3,000 \mathrm{x} \mathrm{g}$ for $5 \mathrm{~min}$ at room temperature. The plasma was then removed and the samples were subjected to Sebia automatic electrophoresis using the Sebia MINICAP (Sebia, Lisses, France) and analyzed with Phoresis CORE v7.4.7 software (Sebia). The results revealed that the proband had $\beta$-thalassemia, whereas his mother and sister suffered from microcytic hypochromic anemia (Table I); the father was phenotypically normal.

To determine the genetic background of this case, peripheral blood DNA was obtained from all available family members for full clinical genetic testing for thalassemia. Control peripheral blood DNA was collected from two disease-free volunteers (34-year-old male; 25-year-old female; classed as disease-free based on normal hemoglobin levels identified via routine blood tests and Sebia automatic electrophoresis) who were recruited from within the Department of Pediatrics (Affiliated Hospital of Zunyi Medical University, Zunyi, Guizhou). Sanger sequencing combined with reverse
Table I. Results of routine blood test and hemoglobin electrophoresis.

\begin{tabular}{lccccc}
\hline Variable & $\begin{array}{c}\text { Normal } \\
\text { range }\end{array}$ & Proband & Father & Mother & Sister \\
\hline $\mathrm{RBC}\left(\mathrm{x} 10^{12}\right)$ & $4.0-5.5$ & 2.85 & 3.9 & 2.74 & 2.67 \\
$\mathrm{MCV}(\mathrm{f} 1)$ & $80-100$ & 69.4 & 82 & 75 & 74 \\
$\mathrm{MCH}(\mathrm{pg} / \mathrm{cell})$ & $26-38$ & 21.9 & 29.5 & 23.7 & 23.5 \\
$\mathrm{MCHC}(\mathrm{g} / \mathrm{l})$ & $300-360$ & 316 & 378 & 340 & 334 \\
$\mathrm{Hb}(\mathrm{g} / \mathrm{l})$ & $120-160$ & 62.0 & 112 & 105 & 90 \\
$\mathrm{HbA}(\%)$ & $>95$ & 78.2 & 97.3 & 95.9 & 95.2 \\
$\mathrm{HbA} 2(\%)$ & $1-3$ & 3.8 & 2.0 & 3.5 & 3.6 \\
$\mathrm{HbF}(\%)$ & $<2$ & 18.0 & 0.1 & 0.2 & 0.5 \\
\hline
\end{tabular}

$\mathrm{Hb}$, hemoglobin; $\mathrm{HbF}$, fetal hemoglobin; $\mathrm{MCH}$, mean corpuscular hemoglobin; MCHC, mean corpuscular hemoglobin concentration; MVC, mean corpuscular volume; RBC, red blood cells.

Table II. Thalassemia genotypes of the proband and family members.

\begin{tabular}{ll}
\hline Individual & \multicolumn{1}{c}{ Genotype } \\
\hline Proband & $\beta^{\mathrm{IVS}-\mathrm{II}-654 / \beta^{\mathrm{N}} ; H B A 2: \mathrm{c} .46 \mathrm{G}>\mathrm{A} ;}$ \\
& $H B B: \mathrm{c} .316-148 \mathrm{G}>\mathrm{T} ; \mathrm{SEA}-H P F H$ \\
Father & $\mathrm{SEA}-H P F H / \beta^{\mathrm{N}}$ \\
Mother & $\beta^{\mathrm{IVS}-\mathrm{II}-654} / \beta^{\mathrm{N}} ; H B A 2: \mathrm{c} .46 \mathrm{G}>\mathrm{A}$ \\
Sister & $\beta^{\mathrm{IVS}-\mathrm{II}-654} / \beta^{\mathrm{N}}$
\end{tabular}

$H B A 2$, hemoglobin subunit $\alpha 2$; HBB, hemoglobin subunit $\beta$; $\mathrm{N}$, normal; SEA- $H P F H$, Southeast Asian-type-hereditary persistence of fetal hemoglobin.

transcription-quantitative PCR (RT-qPCR) were used to detect the 338 known types of globin gene sequence mutations that lead to thalassemia. RT-qPCR was performed to detect the unknown $\alpha$ - and $\beta$-globin genes, and was performed as described previously $(7,8)$. Densitometry was performed using StepOne ${ }^{\mathrm{TM}}$ v2.0 software (Thermo Fisher Scientific, Inc.). The results were normalized to those of GAPDH and the $2^{-\Delta \Delta C q}$ method was used (9). For statistical analysis, a one-way analysis of variance was performed on SPSS v17.0 software (SPSS, Inc., Chicago, IL, USA), and a Dunnett's post hoc test was used for multiple comparison; $\mathrm{P}<0.05$ was considered to indicate a statistically significant difference. The data indicated that the proband had compound mutations of the heterozygous IVS-II-654(C>T) $\beta^{+}$, Southeast Asian (SEA)-type-hereditary persistence of fetal hemoglobin (SEA-HPFH) deletion (NC-000011.9:g.5222878-5250288del) (10), HBA2:c.46G >A heterozygous, and $H B B$ :c.316-148G $>$ T heterozygous (Fig. 1). Although Sanger sequencing indicated that the father had a normal IVS-II-654 gene, results from RT-qPCR (Fig. 1E) indicated that he carried a SEA-HPFH mutation (a deletion of the $\beta$ chain), which was verified by Gap-PCR. Gap-PCR was applied to detect $5 \alpha$-thalassemia deletions including the SEA, $\alpha-3.7, \alpha-4.2$, Filipino and Thailand deletions, and 


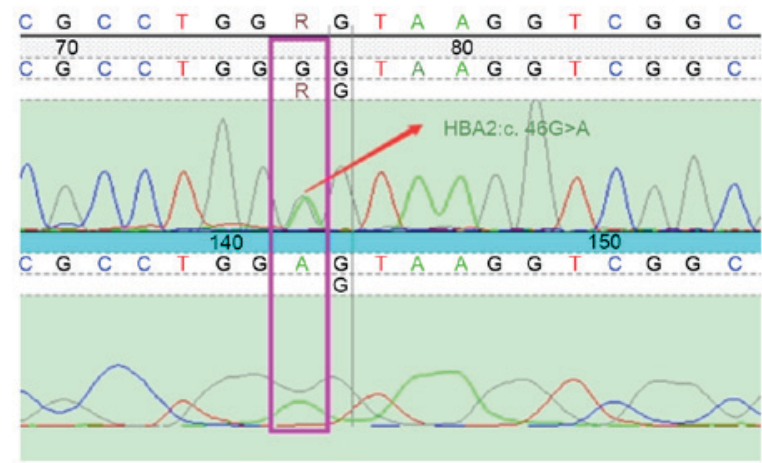

B

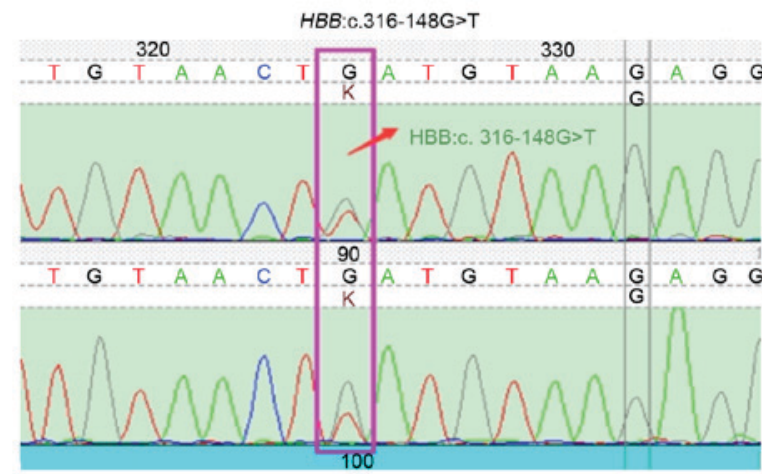

C

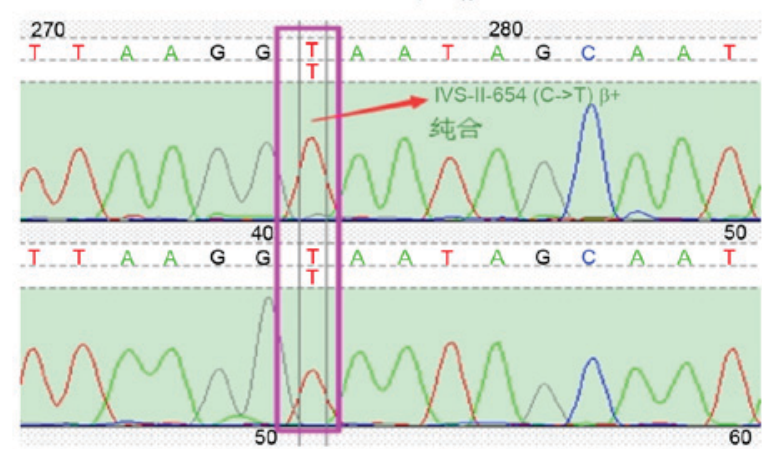

D

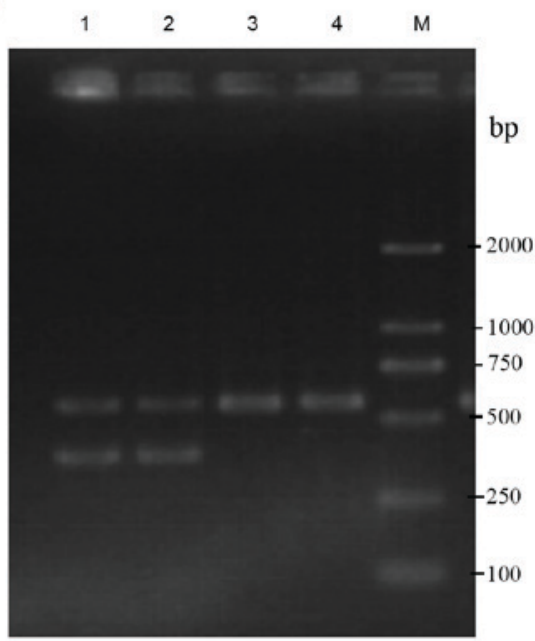

E

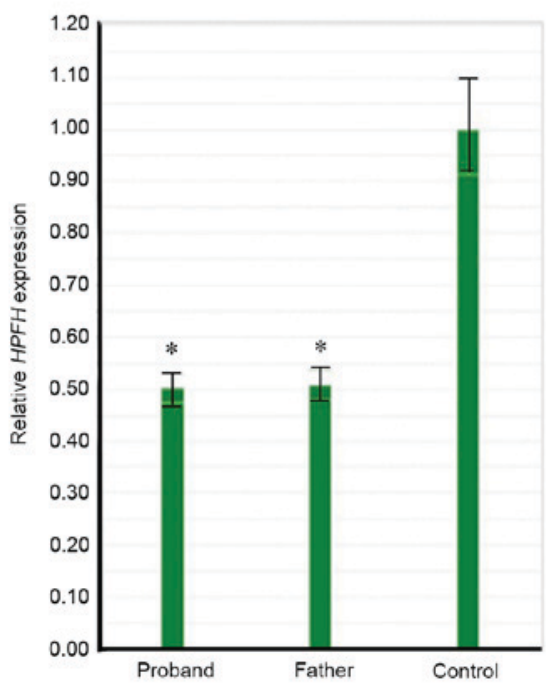

Figure 1. Identification of our mutated genes in the proband by DNA sequencing and gel electrophoresis. Sanger sequencing of the mutations: (A) $H B A 2: c .46 \mathrm{G}>\mathrm{A}$; (B) $H B B$ :c.316-148G > T; and (C) $H B B$ :IVS-II-654(C>T) $\beta^{+}$. Mutated nucleotides are outlined with a magenta box. (D) Identification of the $H P F H$ deletion by gel electrophoresis; the lower bands indicated DNA fragment deletion in the proband (lane 1) and father (lane 2), whereas the normal controls showed one regular band (lanes 3 and 4). (E) Reverse transcription-quantitative polymerase chain reaction demonstrated that lower expression of the $H P F H$ gene in proband and father compared to the normal control. "P<0.05 vs. control. $H B A 2$, hemoglobin subunit $\alpha 2 ; H B B$, hemoglobin subunit $\beta$; $H P F H$, hereditary persistence of fetal hemoglobin; Normal controls, blood DNA samples collected from disease-free volunteers.

was performed as described previously (11). The mother of the proband was a carrier of the compound heterozygous mutations IVS-II-654(C>T) $\beta^{+}$and $H B A 2: c .46 \mathrm{G}>\mathrm{A}$, and his sister inherited the IVS-II-654(C>T) $\beta^{+}$heterozygous mutation from the mother (Figs. 1 and 2; Table II). Based on the above data, the proband was identified as having a somatic mutation $H B B$ :c.316-148G $>$ T, and inherited the other thalassemia mutations from his parents: That is, the SEA-HPFH mutation from the father and the IVS-II-654(C>T) $\beta^{+}$allele and HBA2:c.46G>A mutation from the mother (Fig. 2). Thus, the proband clinically displayed heavy thalassemia, whereas his mother and sister exhibited weaker manifestations of the disease.

Based on previous reports $(12,13)$, it was determined that $H B A 2: c .46 \mathrm{G}>\mathrm{A}$ and $H B B: c .316-148 \mathrm{G}>\mathrm{T}$ were novel alterations located near the known mutations in the thalassemia mutation

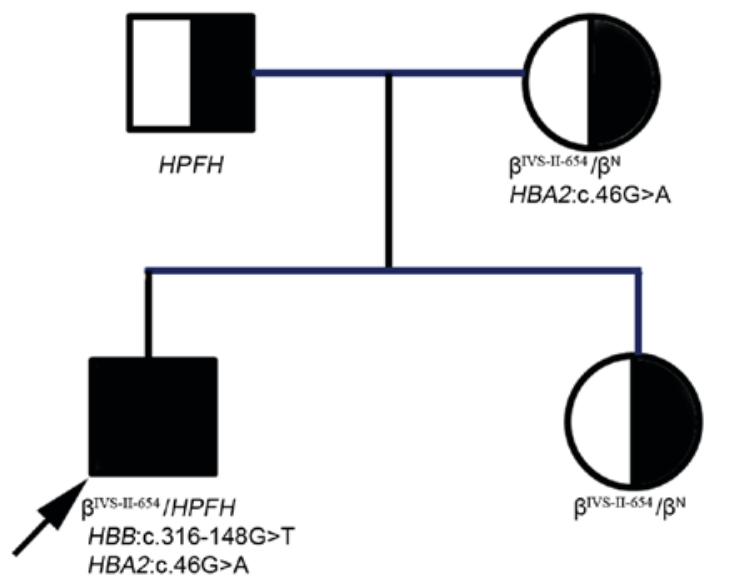

Figure 2. Pedigree and genetic mutations of thalassemia in the family of the proband (arrow). 
Table III. Adjacent positions of novel mutations in the thalassemia mutation database.

\begin{tabular}{|c|c|}
\hline Novel mutations & Known adjacent mutations \\
\hline IVS-II-654(C>T) & 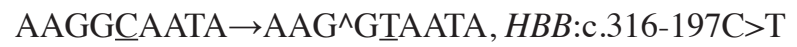 \\
\hline IVS-II-705(T>G) & GATGTAAGA $\rightarrow$ GA $\underline{G}^{\wedge}$ GTAAGA, $H B B: c .316-146 \mathrm{~T}>\mathrm{G}$ \\
\hline IVS-II-726(A>G) & (adjacent sequence unavailable) $H B B: c .316-125 \mathrm{~A}>\mathrm{G}$ \\
\hline IVS-II-745(C>G) & $\mathrm{CAGCTACCAT} \rightarrow \mathrm{CAG}^{\wedge} \underline{\mathrm{G}}^{\prime}, H B B: \mathrm{c} .316-106 \mathrm{C}>\mathrm{G}$ \\
\hline IVS-II-661 (A>G) & (adjacent sequence unavailable) $H B B: c .316-90 \mathrm{~A}>\mathrm{G}$ \\
\hline Hb Ottawa, $\alpha 2$ or $\alpha 1$ & 15(A13)Gly $>$ Arg, $H B A 2: c .46 \mathrm{G}>\mathrm{C}$ \\
\hline
\end{tabular}

Underlined bases indicate mutated nucleotides. $H B A 2$, hemoglobin subunit $\alpha 2$; $H B B$, hemoglobin subunit $\beta ;$; , indicates a truncation, the sequence behind was omitted.

Table IV. HLA type matching results of the proband with his parents and sister.

\begin{tabular}{lccccc}
\hline Case & HLA-A & HLA-B & HLA-C & HLA-DRB1 & HLA-DQB1 \\
\hline Proband & 0301,1101 & 2705,4001 & 0202,0702 & 1001,1202 & 0501,0301 \\
Father & 0301.3303 & 2705,5801 & 0202,0302 & 0301,1001 & 0501,0201 \\
Sister & 0301,1101 & 2705,4001 & 0202,0702 & 1001,1202 & 0501,0301 \\
Mother & 1101,1102 & 4001,4601 & 0102,0702 & 0901,1202 & 0301,0303
\end{tabular}

HLA, human leukocyte antigen.

databases (12) (www.globin.bx.psu.edu/hbvar; www.ncbi.nlm. nih.gov/clinvar/?term=HBB[gene] AND single_gene[prop]) (Table III). HBA2:c.46G $>$ A leads to an amino acid replacement (p.Gly16Ser) that causes a hemoglobin disease, whereas $H B B: c .316-148 \mathrm{G}>\mathrm{T}$ is a mutation in intron 2 of $H B B$, the pathogenic effect of which is unclear.

The HbF level of the proband was considerably high (18\%; Table I), which was consistent with previous reports $(1,2,14-16)$. Small-scale deletions or single-base mutations in the $H B B$ gene may result in low $\mathrm{HbF}$ levels (0.5-6.0\%), whereas large-scale deletions may cause high levels of $\mathrm{HbF}(6.0-15.0 \%)(16,17)$. HbF levels $>15 \%$ may result from compound mutations, such as a large-scale deletion combined with other mutations $(16,17)$. Upon determination of the genetic background of the proband, it was decided that a BMT should be performed. Firstly, the HLA types of the proband and other family members were determined through high-resolution HLA testing by PCR-sequence based typing. Briefly, DNA was extracted from the proband and family members then amplified by PCR using HLA Class I (exons 1-8) and HLA Class II (exons 2-4) primers (PCR primer sequences were patented and withheld by the Beijing Genomics Institute-Shenzhen), and the PCR product was purified for sequencing via the aforementioned Sanger sequencing methodology. The sequencing results indicated that the HLA type of the proband was fully matched with their sister (Table IV), thus the sister was selected as the bone marrow donor, and BMT was conducted involving the proband and sister. To monitor the results of the BMT, follow-up testing was performed using fluorescence in situ hybridization (FISH). Peripheral blood ( 2 ml) were

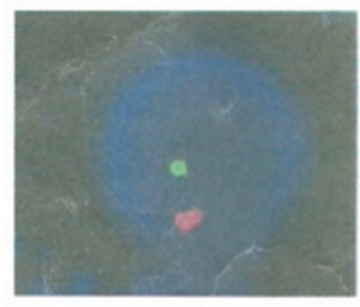

$X Y(1 \%)$

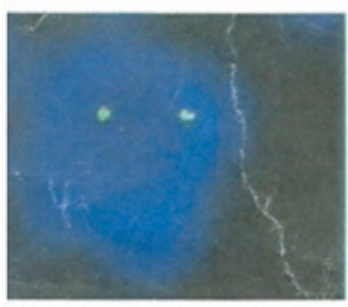

$X X(99 \%)$
Figure 3. The CSPX/CSPY genetic testing by fluorescence in situ hybridization indicated that the donor cells accounted for $99 \%$ in the blood of the proband $30^{+}$days post-bone marrow transplantation. The red signal identifies the $\mathrm{Y}$ chromosome and the green signal identifies the $\mathrm{X}$ chromosome. $\mathrm{XY}$ cells were from the proband, and XX cells were from the donor sister. CSPX, centromeric specific probe for the $\mathrm{X}$ chromosome.

collected from the proband and cultured in the presence of a mitogen [KaryoMAX ${ }^{\circledR}$ Phytohemagglutinin (M-Form; PHA); cat. no. 10576; Thermo Fisher Scientific, Inc.] for $68 \mathrm{~h}$ at $37^{\circ} \mathrm{C}$, then $0.05-0.1 \mu \mathrm{g} / \mathrm{ml}$ KaryoMAXColcemid ${ }^{\circledR}$ Solution (mitotic inhibitor; cat. no. 15210; Thermo Fisher Scientific, Inc.) was added to the culture at room temperature for $20 \mathrm{~min}$. Cells were subsequently treated with $5 \mathrm{ml}$ hypotonic solution $(0.068 \mathrm{M} \mathrm{KCl})$ at room temperature for $15 \mathrm{~min}$, then $1 \mathrm{ml}$ fresh ice cold fixative (absolute methanol:glacial acetic acid, 3:1) was added, and the cells were spun down at $500 \mathrm{x} \mathrm{g}$ at room temperature for $7 \mathrm{~min}$. The supernatant was then removed, and $5 \mathrm{ml}$ of fresh, ice-cold fixative was added drop by drop (with continuous vortexing) at $4^{\circ} \mathrm{C}$ for $20 \mathrm{~min}$. This fixation step was repeated until the supernatant became clear, then the cell pellet was resuspended in $1.5 \mathrm{ml}$ 
fixation solution and placed onto slides; the slides were left at $55^{\circ} \mathrm{C}$ overnight, then they were kept at $4^{\circ} \mathrm{C}$ for subsequent use. For FISH, the prepared slides were incubated at $50^{\circ} \mathrm{C}$ for $2.5 \mathrm{~h}$, then denatured in $70 \%$ formamide at $70^{\circ} \mathrm{C}$ for 2 min, followed by dehydration in a series of ethanol solutions $(70,80,90$ and 100\%) at room temperature for $2 \mathrm{~min}$ each. The slides were subjected to hybridization using a denatured CSPX/CSPY probe mixture (Beijing GP Medical Technologies, Ltd., Beijing, China; denatured at $75^{\circ} \mathrm{C}$ for $5 \mathrm{~min}$ then $0^{\circ} \mathrm{C}$ for $5-10 \mathrm{~min}$ ) at $37^{\circ} \mathrm{C}$ for $15-17 \mathrm{~h}$. Following hybridization, the slides were washed three times $(10 \mathrm{~min}$ each) in $50 \%(\mathrm{v} / \mathrm{v})$ formamide containing $2 \mathrm{X} \mathrm{SSC}$, then once in $2 \mathrm{X} \mathrm{SSC}$ for $10 \mathrm{~min}$ and once in $2 \mathrm{X}$ SSC containing $0.1 \%$ NP-40 (Amresco LLC, Solon, OH, USA) for $5 \mathrm{~min}$. The slides were then dehydrated in $70 \%$ ethanol for 3 min and allowed to air dry at room temperature. A total of $12 \mu \mathrm{l}$ DAPI (Beijing GP Medical Technologies, Ltd.) was added to each slide and incubated at room temperature for $20 \mathrm{~min}$ in the dark followed by analysis using a fluorescence microscope (OLYMPUS-BX51; Olympus Corporation, Tokyo, Japan). The results demonstrated that the donor cells (karyotype: 46, XX) accounted for $99 \%$ of the blood cells in the proband 30 days post-treatment (Fig. 3), and the proband's blood was normal 60 days following BMT; four months post-BMT, the blood type of the proband was transformed from type $\mathrm{O}$ to type A, which was the same as the donor (the proband's sister). Six months following BMT, the proband exhibited a thalassemia genotype that was consistent with his sister; thus, no further blood transfusions were required.

\section{Discussion}

Thalassemia is an inherited, autosomal recessive blood disorder that is characterized by an abnormal formation of hemoglobin. Patients with thalassemia make less hemoglobin, and this hemoglobin is abnormal; patients also have fewer circulating red blood cells, which results in mild to severe microcytic anemia $(1,2,15,18)$. Currently, the diagnosis of thalassemia relies on routine blood testing combined with blood hemoglobin electrophoresis and thalassemia gene detection (17). Conventional thalassemia gene screening methods only detect known point mutations. In the present study, the single-gene screening method was noted to miss some potential genetic changes; for example, Sanger sequencing failed to detect the SEA-HPFH deletion mutation of the father, and prior to RT-qPCR testing the proband was initially misdiagnosed as having a IVS-II-654(C>T) $\beta^{+}$homozygous mutant. These findings suggested that multiple thalassemia gene screening methods may be required for precise genotyping of the disease.

The mother of the proband carried the IVS-II- $654(\mathrm{C}>\mathrm{T})$ mutation located on chromosome 11 , which is a commonly identified $\beta$-thalassemia mutation in Chinese people $(14,19)$, and which results in a splicing error that produces abnormal mRNA and hemoglobin protein, eventually causing $\beta$-thalassemia (20). Although the IVS-II-654(C>T) $\beta^{+}$heterozygous mutation may cause 'light' $\beta$-thalassemia that does not require special treatment, homozygous and compound heterozygous mutations may lead to severe disease and the affected patient usually requires regular blood transfusions. In the present case, the proband inherited the IVS-II- $654(\mathrm{C}>\mathrm{T}) \beta^{+}$ mutation from his mother and the SEA-HPFH deletion from his father, which constituted a compound heterozygous mutation that led to heavy $\beta$-thalassemia. The SEA-HPFH mutation is a rare $\beta$-thalassemia genotype in the Chinese population; it was first identified in Vietnamese and Cambodian patients $(21,22)$. SEA-HPFH mutations involve a large DNA deletion that includes the $\beta$-globin gene cluster $(18,21,23)$. The deletion range covers NC-000011.9:g. 5222878-5250288del, missing the entire $\beta$-globin gene and its 3 'hyper sensitive site $1(10,24,25)$, which may not be detected by the common $\beta$-thalassemia detection assays. The average SEA-HPFH carrier exhibits no clinical symptoms and their peripheral blood cells appear completely normal. However, when this mutation coincides with another $\beta$-gene mutation and/or constitute compound heterozygous mutations, it may lead to severe or heavy $\beta$-thalassemia, which is what occurred in the present case study.

To the best of our knowledge, the present study was the first to identify the HBA2:c.46G $>$ A mutation in $\alpha$ chain on chromosome 16. This mutation leads to a Gly16Ser amino acid replacement; however, whether it is causative of thalassemia requires further analysis. The HBB:c.316-148G $>\mathrm{T}$ mutation is located in intron 2 of the $\beta$-globin gene, and was determined to be a novel somatic alteration identified in the proband. The alteration does not change the protein structure; however, whether it affects the generation of mRNA and causes the disease also merits further investigation. These novel mutations enriched the thalassemia mutation spectrum in the Chinese population, which may be helpful in future genetic counseling and clinical diagnosis.

Currently, hematopoietic stem cell transplantation (HSCT) is the only effective way to cure severe $\beta$-thalassemia in the clinical practice $(15,26,27)$. The influence on transplant success rate of donor mainly depends on the HLA typing on chromosome 6 (28). In the present case, the HLA type of the sister completely matched that of the proband, which led to successful BMT and cured the patient of the disease.

\section{Acknowledgements}

The authors thank the many clinicians, data managers and research staff who participated in this project.

\section{References}

1. Higgs DR, Engel JD and Stamatoyannopoulos G: Thalassaemia. Lancet 379: 373-383, 2012.

2. Muncie HL Jr and Campbell J: Alpha and beta thalassemia. Am Fam Physician 80: 339-344, 2009.

3. Cai R, Li L, Liang X, Liu Z, Su L, Li W, Zhu Q, Mo Q, Pan L, Ouyang $\mathrm{H}$, et al: Prevalence survey and molecular characterization of alpha and beta thalassemia in Liuzhou city of Guangxi. Zhonghua Liu Xing Bing Xue Za Zhi 23: 281-285, 2002 (In Chinese).

4. Xu XM, Zhou YQ, Luo GX, Liao C, Zhou M, Chen PY, Lu JP, Jia SQ, Xiao GF, Shen X, et al: The prevalence and spectrum of alpha and beta thalassaemia in Guangdong Province: Implications for the future health burden and population screening. J Clin Pathol 57: 517-522, 2004.

5. Zhang J, Zhu BS, He J, Zeng XH, Su J, Xu XH, Li SY, Chen H and Zhang YH: The spectrum of a- and b-thalassemia mutations in Yunnan Province of Southwestern China. Hemoglobin 36: 464-473, 2012. 
6. Hu ZH, Liu YL, Zeng ZY, Zhang XL and Zhu QY: Beta-thalassemia majar caused by compound heterozygosity for +40 to -43 (-AAAC), IVS-2-654 (C to T) and codon 41/42 (-TCTT). Zhonghua Yi Xue Yi Chuan Xue Za Zhi 25: 418-420, 2008 (In Chinese).

7. Babashah S, Jamali S, Mahdian R, Nosaeid MH, Karimipoor M, Alimohammadi R, Raeisi M, Maryami F, Masoudifar M and Zeinali S: Detection of unknown deletions in beta-globin gene cluster using relative quantitative PCR methods. Eur J Haematol 83: 261-269, 2009.

8. Fallah MS, Mahdian R, Aleyasin SA, Jamali S, Hayat-Nosaeid M, Karimipour M, Raeisi M and Zeinali S: Development of a quantitative real-time PCR assay for detection of unknown alpha-globin gene deletions. Blood Cells Mol Dis 45: 58-64, 2010.

9. Livak KJ and Schmittgen TD: Analysis of relative gene expression data using real-time quantitative PCR and the 2(-Delta Delta C(T)) method. Methods 25: 402-408, 2001

10. Liu Z, Zhong X, Li Z and Xu X: Rapid detection of an HPFH deletion by PCR amplification with three primers bridging the breakpoint. Zhonghua Yi Xue Yi Chuan Xue Za Zhi 16: 41-43, 1999 (In Chinese)

11. Chong SS, Boehm CD, Cutting GR and Higgs DR: Simplified multiplex-PCR diagnosis of common southeast asian deletional determinants of alpha-thalassemia. Clin Chem 46: 1692-1695, 2000.

12. Giardine B, Borg J, Viennas E, Pavlidis C, Moradkhani K, Joly P, Bartsakoulia M, Riemer C, Miller W, Tzimas G, et al: Updates of the HbVar database of human hemoglobin variants and thalassemia mutations. Nucleic Acids Res 42 (Database Issue) D1063-D1069, 2014

13. Carlice-Dos-Reis T, Viana J, Moreira FC, Cardoso GL, Guerreiro J, Santos S and Ribeiro-Dos-Santos Â: Investigation of mutations in the HBB gene using the 1,000 genomes database. PLoS One 12: e0174637, 2017.

14. Long $G$ and Zhang J: Hemoglobin \& Hemoglobinopathies. Guangxi Science \& Technology Press, Guangxi, pp233-235, 2003.

15. Cao A and Galanello R: Beta-thalassemia. Genet Med 12: 61-76, 2010.

16. Mosca A, Paleari R, Leone D and Ivaldi G: The relevance of hemoglobin $\mathrm{F}$ measurement in the diagnosis of thalassemias and related hemoglobinopathies. Clin Biochem 42: 1797-1801, 2009.

17. Liu G and Sun S: The laboratory diagnosis of thelassemia: Selection and evaluation of tests and methods. Chin J Lab Med 35: 385-387, 2012
18. Bollekens JA and Forget BG: Delta beta thalassemia and hereditary persistence of fetal hemoglobin. Hematol Oncol Clin North Am 5: 399-422, 1991.

19. Zhang J, He J, Zeng XH, Ge SJ, Huang Y, Su J, Ding XM, Yang JQ, Cao YJ, Chen H, et al: Genetic heterogeneity of the $\beta$-globin gene in various geographic populations of Yunnan in southwestern China. PLoS One 10: e0122956, 2015.

20. Huang SZ, Zeng FY, Ren ZR, Lu ZH, Rodgers GP, Schechter AN and Zeng YT: RNA transcripts of the beta-thalassaemia allele IVS-2-654 C-->T: A small amount of normally processed beta-globin mRNA is still produced from the mutant gene. Br J Haematol 88: 541-546, 1994.

21. Changsri K, Akkarapathumwong V, Jamsai D, Winichagoon $\mathrm{P}$ and Fucharoen S: Molecular mechanism of high hemoglobin F production in Southeast Asian-type hereditary persistence of fetal hemoglobin. Int J Hematol 83: 229-237, 2006.

22. Zheng W, Liu Y, Chen D, Rong K, Ge Y, Gong C and Chen H: Complex interaction of $\mathrm{Hb} \mathrm{Q}$-Thailand and $\mathrm{Hb} \mathrm{E}$ with alpha(0)-thalassemia and hereditary persistence of fetal hemoglobin in a Chinese family. Ann Hematol 89: 883-888, 2010.

23. Xiu X: The molecular basis of the $\delta \beta$-thalassemia for HPFH and deletion seen in the Chinese. Chin J Med Genet 15:315-317, 1998.

24. Bhardwaj U and McCabe ER: Multiplex-PCR assay for the deletions causing hereditary persistence of fetal hemoglobin. Mol Diagn 9: 151-156, 2005 .

25. Xu XM, Li ZQ, Liu ZY, Zhong XL, Zhao YZ and Mo QH: Molecular characterization and PCR detection of a deletional HPFH: Application to rapid prenatal diagnosis for compound heterozygotes of this defect with beta-thalassemia in a Chinese family. Am J Hematol 65: 183-188, 2000

26. Smiers FJ, Krishnamurti L and Lucarelli G: Hematopoietic stem cell transplantation for hemoglobinopathies: Current practice and emerging trends. Pediatr Clin North Am 57: 181-205, 2010.

27. Caocci G, La Nasa G, d'Aloja E, Vacca A, Piras E, Pintor M, Demontis R and Pisu S: Ethical issues of unrelated hematopoietic stem cell transplantation in adult thalassemia patients. BMC Med Ethics 12: 4, 2011.

28. Valcárcel D, Sierra J, Wang T, Kan F, Gupta V, Hale GA, Marks DI, McCarthy PL, Oudshoorn M, Petersdorf EW, et al: One-antigen mismatched related versus HLA-matched unrelated donor hematopoietic stem cell transplantation in adults with acute leukemia: Center for International blood and marrow transplant research results in the era of molecular HLA typing. Biol Blood Marrow Transplant 17: 640-648, 2011. 